\title{
Photochemistry, Photophysics and Photobiology
}

It is a special privilege and a great honour for us to pen a few words as editorial for this special issue of the Journal of Chemical Sciences on Photochemistry in honour of M V George. India has a great legacy of contributions to the understanding of photochemistry. More than 3500 years ago, ancient Indian healers had recognised the power of light to heal, now known as phototherapy, when they used plant extracts and sunlight to treat leucoderma. There have also been major contributions to the modern understanding of photochemistry from Indian scientists like J C Ghosh, N R Dhar, S S Bhatnagar and Bawa Kartar Singh. Interestingly, much of the great work done by these scientists in photochemistry happened in the late 1920s and early 1930s. This period was also very important time for the development of modern photochemistry internationally with seminal contributions from the likes of Stern and Volmer, Frank and Condon, Jablonski, Lewis and Kasha, whose names have today become part of the language of photochemistry.

Manapurathu Verghese George (MVG), a renowned organic chemist who holds a unique place in the growth of photochemistry research in India was born around this time, 1928 to be precise, in Kollam. His parents who hailed from Ashtamudi, one of the most scenic backwater hubs of Kerala, had moved to Kollam, to run a successful water transport business. It was here, in these idyllic settings, far removed from the leading centres of education or research of those days, that MVG the second of five children grew up and had his early schooling. Following his school education in Kollam, he went on to study at the Union Christian College, Alwaye, from where he obtained his B.Sc and M.Sc degrees in Chemistry. After teaching in the same college for a year, he moved to St. John's College, Agra to work on his $\mathrm{PhD}$ in organic chemistry under the supervision of P I Ittyerah on some aspects of Perkin and Knoevanagel condensation reactions. Subsequently, he went on to do his postdoctoral research with some of the most renowned organic chemists of that time. He had worked with George F Wright at the University of Toronto, Henry Gilman at Iowa State University, Melvin S
Newman at the Ohio State University, Sir Derek Barton at the Imperial College of Science and Technology, London, and Rolf Huisgen at the University of München. The exposure to these unique personalities, their work culture and variety of research topics covering various aspects of physical organic chemistry, electron transfer reactions and photochemistry among others had a significant impact on MVG, who later developed his famous and signature style of working on his return to India.

Soon after his return to India, he was appointed at the Department of Chemistry of IIT Kanpur in April 1963, where he joined with C N R Rao, P T Narasimhan and many others to establish one of the best departments of chemistry in India. This department has produced outstanding chemists of the country over the years and continues to be one of the leading centres in India for research and teaching in chemistry.

The research group he established at IIT, Kanpur focussed on mechanistic aspects of thermal and photochemical organic transformations, including the study of electron transfer processes, organic reactions and functional group transformations, organic phototransformations. His initial interest was in the study of radical anions and dianions generated by electron transfer reactions with alkali metals and their use in the synthesis of heterocycles. His group subsequently went on to study mechanistic aspects of the oxidation of a variety of organic substrates, employing manganese dioxide and nickel peroxide. The ability of these oxides to bring about selective transformations of functional groups was explored to develop newer methods of synthesising heterocycles.

MVG's early interest in photochemistry started with the aim of developing photochemical procedures for decarboxylation of secondary and tertiary carboxylic acids through the photodecarbonylation of corresponding acyl and aroyl xanthates, carrying out detailed investigations on the photochemistry of these substrates, including the characterization of the transient intermediates involved in these reactions. This was followed by interesting studies on the photochemistry of a class of 
mesoionic molecules known as sydnones. He was able to show that sydnones underwent phototransformations to yield triazoles as the major product via formation of bisphenylazostilbene which in turn underwent cyclization to yield 1,3-dipolar intermediates. The trapping of these intermediates with various dipolarophiles was found to be a facile method for the synthesis of complex bicycloheteraromatics. Subsequently, he moved on to study the mechanism of the photochemistry of complex molecules including several multichromophoric systems such as dibenzobarrelenes containing both the 1,2-dibenzoyl and barrelene chromophores. During this period, he developed a strong association with R W Fessenden and P K Das of the Radiation Laboratory ( Rad $\mathrm{Lab}$ ) of the University of Notre Dame to carry out timeresolved studies on the transients formed in several of the molecular systems mentioned above. This association with Rad Lab continued way past his superannuation from IIT Kanpur. Many would have been fascinated seeing a senior MVG in a starched Lab coat at the Rad Lab, heading toward the cellar with his trolley containing his usual collection of sharpened pencils, neatly stacked glassware, and meticulously maintained workbook to conduct transient spectroscopic studies with the same excitement and enthusiasm of a fresh young $\mathrm{PhD}$ student.

After his superannuation from IIT Kanpur in 1988, he moved back to his home state of Kerala to work as Professor Emeritus at the Regional Research Laboratory at Trivandrum, an institute under the CSIR umbrella. Here with the help of a few young scientists, he set up the Photochemistry Research Unit, which later renamed as the Photosciences and Photonics Section under the Chemical Sciences Division of RRL-T became one of the leading centres in India for research on photosciences. His presence at RRL$\mathrm{T}$ attracted several leading chemists and photochemists to visit and support the growth of the photochemistry group in the Institute including $\mathrm{C} \mathrm{N} R$ Rao, Mihir Chowdhury, S V Kessar, P Natarajan, Jai Pal Mittal, Balu Venkataraman, S Ranganathan, Darshan Ranganathan, D Balasubramaniam, Prashant V Kamat, Gary Schuster, Klaas Zachariasse, K Kalyanasundaram, Waldemar Adam, Kirti Tennakone, Hiroshi Masuhara, Hiroyuki Nakazumi, Challa Vijay Kumar and many others. His presence also helped in the overall growth and stature of the Institute, which is today known as the National Institute for Interdisciplinary Science and Technology and is one of the leading centres for research in Chemistry and Materials as well as in many other areas.

Within the photochemistry group of what was then RRL-T, he helped to establish a vibrant work culture and encouraged weekly seminars and meetings to discuss and debate some of the latest developments in photochemistry as well as presentations of research work of the group by scientists and their students. During these seminars, students were fascinated to see a senior $\mathrm{MVG}$, never afraid of appearing ignorant, asking questions and having his doubts clarified by young scientists and students. The free and open discussions of the work of the scientists and their students that he encouraged in these meetings led to a lot of cross-pollination of ideas. His intense interest and curiosity about life and new things in science, of cultures, of people, has been an enduring trait.

While at NIIST, MVG along with C N R Rao established the "Foundation for Capacity Building in Science (FCBS)." Through its annual meetings as well as seminars and workshops organised in various parts of Keralatargeting students and teachers, FCBS has had a significant role in promoting a number of bright young students of Kerala to pursue a career in science.

MVG continues to attend his office at NIIST playing a mentorship role for a new generation of scientists and students. MVG is today recognised in many ways; as a great scientist, expert organic chemist/photochemist and a great teacher. But one of his most important contributions is his ability to be there, listen to, encourage, enthuse and urge young students and scientists to be the best they can be. It is not surprising therefore to see many of his former students, including some of the B. Tech students he had taught at IIT Kanpur, who are presently highly successful professionals working at some of the leading institutes in the world, visit him to acknowledge the role he had played in shaping their professional and personal lives.

The role of MVG as a mentor for young students and scientists can be best exemplified by the following story: "An eagle chick had fallen off its nest. A kind farmer saw it and carried it back to his farm. The farmer let the little eagle grow up with the chicks of the farm hen, where it grew into a big-sized bird scratching for worms in the farm. A wildlife enthusiast visiting the farm was shocked to see such a magnificent bird, scratching for worms in the farm along with the chickens. He tried to get the eagle to fly first by throwing it off the barn roof and then from a tall tree. Both the times the shaken eagle finds itself back to the ground and continues to scratch for worms. He then throws the eagle off a cliff. Fluttering for some time it finally takes off and flies high, like the king of the sky to a new life with perhaps only occasional nostalgia for its days in the farm." 
MVG has helped many a young person to find that eagle in themselves. On behalf of them and all of us who have been associated with him, we dedicate this special issue of Journal of Chemical Sciences on Photochemistry to Professor Manapurathu Verghese George on the occasion of his $90^{\text {th }}$ birthday and wish him many more years of active service.

We take this opportunity to thank all the authors and the referees for their cooperation in bringing out this special issue. We also thank Professor N. Periasamy, Editor-in-Chief of the Journal of Chemical Sciences for both accepting our proposal and providing guidance in bringing out this special issue. We also acknowledge the help of the editorial staff of the Journal of Chemical Sciences and the publishing and production team of Springer Nature for their assistance in the production of this special issue in a timely manner.

\section{SRINIVASAN CHANDRASEKARAN}

Department of Organic Chemistry, Indian Institute of Science, Bengaluru, India

Email:scn@iisc.ac.in; chandraorgchem@gmail.com

AYYAPPANPILLAI AJAYAGHOSH

National Institute for Interdisciplinary Science and

Technology,

Industrial Estate Post, Thiruvananthapuram, India

Email:ajayaghosh62@gmail.com

SURESH DAS

Kerala State Council for Science, Technology and, Environment, Sasthra Bhavan, Pattom, Thiruvananthapuram, India E-mail:sureshdas55@gmail.com 